\title{
Simulations of Magnetic Recording Trends in Metal Particle Tape
}

\author{
Steven E. STUPP, Hugo A. J. CRAMER, and Steven B. LUITJENS
}

Philips Research Laboratories, Prof. Holstlaan 4, 5656 AA Eindhoven, The Netherlands

\begin{abstract}
Numerical simulations of the recording performance of metal particle (MP) tapes as a function of improvements in the geometric (head-to-tape distance and tape thickness) and magnetic properties (saturation magnetization and coercivity) of the tapes have been performed. For the tapes considered significant improvements are possible. A total improvement relative to existing MP tapes of $6.9 \mathrm{~dB}$ at a wavelength of $0.5 \mu \mathrm{m}$ is predicted. Key words: metal particle (MP) tape, metal evaporated (ME) tape, numerical simulations, Preisach model, StonerWohlfarth model.
\end{abstract}

\section{INTRODUCTION}

Recently some improved MP tapes have been produced and studied.[1] In this work we simulate the properties of improved MP tapes. We have simulated the effects that modifications of the geometric and magnetic properties of metal particle (MP) tapes have on their magnetic recording output signals. These simulations were performed with a self-consistent numerical model of the recording process. The central component of the model is a moving-Preisach Stoner-Wohlfarth vector hysteresis model. Both the recording and hysteresis models have been quantitatively compared to experimental data to confirm that the models yield quantitatively accurate results. The recording model has been found to have an absolute accuracy of $2 \mathrm{~dB}$, and more importantly for this work, has a relative accuracy of 1 $\mathrm{dB}$. Thus we have confidence that the model can predict trends in media and their consequences for magnetic recording. By theoretically decreasing the tape thickness $\delta$ and the magnetic head-to-tape distance $d$, and increasing coercivity $\mathrm{H}_{c}$, and the saturation magnetization $M_{s}$ of a standard MP tape, a doubling in the output signal at a wavelength of $0.5 \mu \mathrm{m}$ is predicted. The simulated improved MP tapes will have approximately the same output signal at a wavelength of $0.5 \mu \mathrm{m}$ as commercial $\mathrm{Hi}-8 \mathrm{~mm}$ metal evaporated (ME) tapes, though improved ME tapes are expected.[2]

\section{SIMULATIONS}

The details of the hysteresis and recording models have been reported previously. $[3,4]$ We used the hysteresis model to simulate the experimentally determined magnetic properties of an MP tape. The simulated major and remanent loops are shown in Fig. 1. The recording model was then used to simulate the magnetic recording process. A Karlqvist head with a gap width $g$ of $0.25 \mu \mathrm{m}$ and an efficiency of 0.65 was assumed and used to simulate writing on an unrecorded tape.. The tape was initially $0.5 \mu \mathrm{m}$ thick with a head-to-tape distance of $50 \mathrm{~nm}$ (including head hollow out, non-magnetic lubricant layers, and surface roughness). The calculated normalized output signal (normalized to a head with $1 \mathrm{turn}$, a width of $1 \mathrm{~m}$, and a relative speed of $1 \mathrm{~m} / \mathrm{s}$ ) for this initial MP tape, at wavelengths of 1.0 and $0.5 \mu \mathrm{m}$, versus the product of the efficiency, the number of head turns, and the write current amplitude, $\eta \mathrm{NI}$, is shown in Fig. 2. The optimal write current amplitudes for this initial MP tape at 1.0 and 0.5 $\mu \mathrm{m}$ are 14 and $9 \mathrm{~mA}$, respectively $(\mathrm{N}=20$ in our simulations). The write current amplitude in all simulations was chosen to maximize the calculated output signal at a wavelength of $1.0 \mu \mathrm{m}$.

We then systematically decreased $d$ and $\delta$ holding all other parameters fixed. The results of these simulations are shown in Table $I$ as normalized output signals at 1.0 and $0.5 \mu \mathrm{m}$. The effects of decreasing $\mathrm{d}$ and $\delta$ add almost independently, and combined improvements of $1.3 \mathrm{~dB}$ at 1 $\mu \mathrm{m}$ and $4.3 \mathrm{~dB}$ at $0.5 \mu \mathrm{m}$ are predicted. The calculated normalized output signals at 1.0 and $0.5 \mu \mathrm{m}$ versus tape thickness, with $\mathrm{d}$ held fixed at $50 \mathrm{~nm}$, are shown in Fig. 3. The output signal at $1.0 \mu \mathrm{m}$ peaks at a thickness of $0.2 \mu \mathrm{m}$, while the output signal at $0.5 \mu \mathrm{m}$ peaks at a thickness of $0.1 \mu \mathrm{m}$. Note the very small difference between the output signals at 1.0 and $0.5 \mu \mathrm{m}$ at a tape thickness of $0.1 \mu \mathrm{m}$. The difference in the output signal at 1.0 and $0.5 \mu \mathrm{m}$ is directly related to the roll-off in output signal as a function of increasing inverse wavelength through the PW50 (pulsewidth-at-half-maximum) value.[5] The PW50 value is a function of the four main geometric length scales in the problem: the head-to-tape distance, the gap width, the tape thickness, and the recorded transition width.[5] For a lorentzian pulse shape the PW50 value in $\mu \mathrm{m}$ is

$$
P W 50=\frac{V_{1.0 \mu m}-V_{0.5 \mu m}+6.03}{2.73 \cdot 10^{7}},
$$

where the output signals at 1.0 and $0.5 \mu \mathrm{m}\left(\mathrm{V}_{1.0 \mu \mathrm{m}}\right.$ and $\left.V_{0.5 \mu \mathrm{m}}\right)$ are in dBV.[6] Very small PW50 values can be achieved in this thin MP tape at the expense of a reduction 
in the peak output signal. Schematics of the recorded magnetization patterns in the vicinity of a recorded transitions are shown for two tapes $(\mathrm{d}=50 \mathrm{~nm}, \delta=0.5 \mu \mathrm{m}$ and $d=50 \mathrm{~nm}, \delta=0.2 \mu \mathrm{m}$ ) in Figs. $4 \mathrm{a}$ and $4 \mathrm{~b}$ (note the different scales in the two Figs.). The solid lines are guides to the eye and indicate the center and width (25-75\%) of the transitions. Note the partial penetration recording in the thicker tape.

Table I. The effect of improvements in the geometric properties on the calculated output signal. For these simulations $M_{s}=285.4 \mathrm{kA} / \mathrm{m}$, and $H_{c}=152.1 \mathrm{kA} / \mathrm{m}$.

$\begin{array}{ccccc}\text { Simul } & \mathrm{d}(\mathrm{nm}) & \delta(\mu \mathrm{m}) & \mathrm{V}_{1.0}(\mathrm{dBV}) & \mathrm{V}_{0.5}(\mathrm{dBV}) \\ \mathrm{A} & 50 & 0.5 & -22.8 & -34.0 \\ \mathrm{~B} & 50 & 0.2 & -22.5 & -31.9 \\ \mathrm{C} & 35 & 0.5 & -21.8 & -31.8 \\ \mathrm{D} & 35 & 0.2 & -21.5 & -29.7\end{array}$

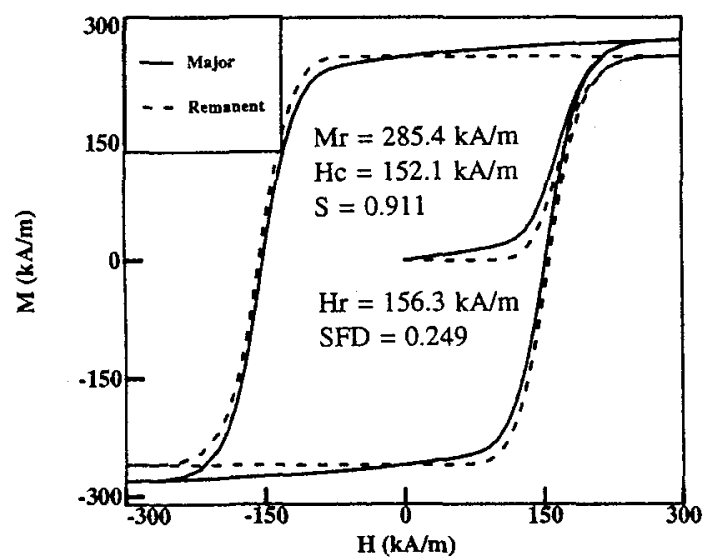

Fig. 1 Calculated major and minor hysteresis loops.

With $\mathrm{d}=35 \mathrm{~nm}$ (this value of $\mathrm{d}$ is on the order of that of ME tape) and $\delta=0.2 \mu \mathrm{m}$ (at thicknesses smaller than this, large variations in the thickness have been observed.[1]) we then increased $\mathrm{H}_{c}$ and $\mathrm{M}_{\mathrm{s}}$ by up to $30 \%$ (the approximate improvement expected in the magnetic layer in the near future[7]) holding all other parameters fixed. The results of these simulations are shown in Table II as normalized output signals at 1.0 and $0.5 \mu \mathrm{m}$. By increasing $\mathrm{H}_{\mathrm{c}}$ and $\mathrm{M}_{\mathrm{s}}$, a combined $2.4 \mathrm{~dB}$ improvement at $1 \mu \mathrm{m}$, and $2.6 \mathrm{~dB}$ improvement at $0.5 \mu \mathrm{m}$ are predicted. The total improvements (including the geometric and magnetic changes) with respect to the initial tape (simulation $\mathrm{A}$ ) are $4.7 \mathrm{~dB}$ and $6.9 \mathrm{~dB}$ at 1.0 and $0.5 \mu \mathrm{m}$ respectively. The calculated normalized output signal versus inverse wavelength curves for simulations $A, D$, and $G$ are shown in Fig. 5. Varying the tape properties effects the $M_{r} \delta$ product (where $M_{r}$ is the remanent magnetization) and the spacing and thickness losses in the expected manner. There is also the expected change in the PW50 values as the geometric lengths are reduced (PW50 $=0.63 \mu \mathrm{m}$ for simulation $\mathrm{A}$. and
$0.52 \mu \mathrm{m}$ for simulation $\mathrm{D}$ ), and as expected almost no change as the magnetic properties are increased (PW50 = $0.51 \mu \mathrm{m}$ for simulation $\mathrm{G}$ ) since the $\mathrm{M}_{\mathrm{r}} \delta / \mathrm{H}_{c}$ ratio does not change appreciably.

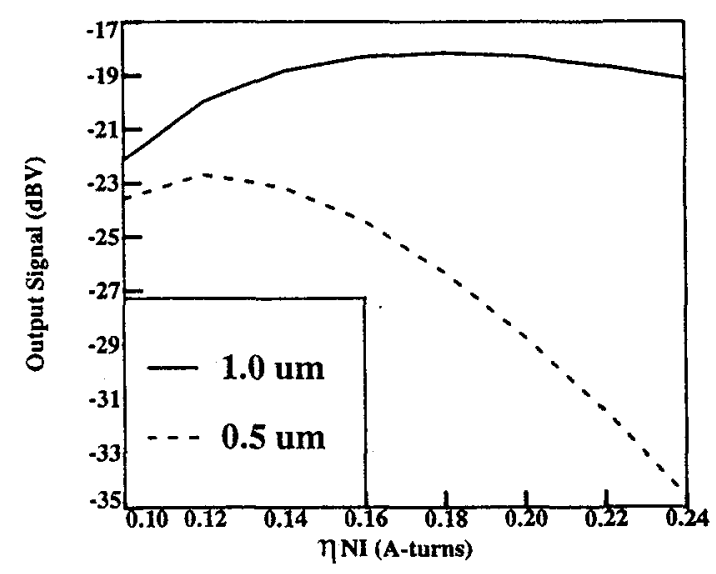

Fig. 2 Calculated output signal at 1.0 and $0.5 \mu \mathrm{m}$ in $\mathrm{dBV}$ versus the product of the efficiency, the number of turns and the write current amplitude $\eta N I$.

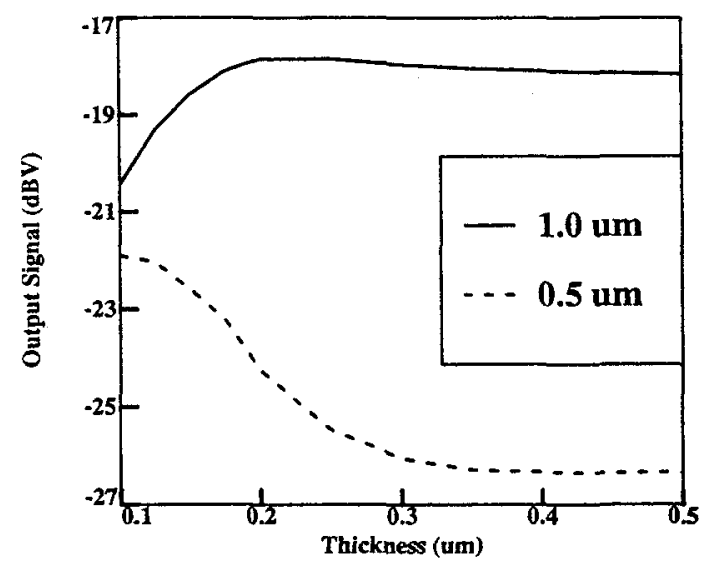

Fig. 3 Calculated output signal at 1.0 and $0.5 \mu \mathrm{m}$ in $\mathrm{dBV}$ versus tape thickness $\delta$ in $\mu \mathrm{m}(d=50 \mathrm{~nm})$.

For purposes of comparison recording measurements were performed on a current Sony Hi-8mm ME tape using a MIG head (width $=10 \mu \mathrm{m}, \mathrm{g}=0.25 \mu \mathrm{m}, \mathrm{N}=20$ ) on a rotating drum apparatus. Square wave signals were recorded on an ac-erased tape. The square wave amplitude was chosen to maximize the output signal at $1.0 \mu \mathrm{m}$. Output signals at the fundamental harmonic of the square wave were measured with a spectrum analyzer. The normalized output ( $w=1 \mu \mathrm{m}, \mathrm{N}=1, \mathrm{v}=1 \mathrm{~m} / \mathrm{s}$ ) at 1.0 and $0.5 \mu \mathrm{m}$ for the ME tape are $-23.0 \mathrm{dBV}$ and $-26.7 \mathrm{dBV}$, respectively. The PW50 value for the ME tape is $0.36 \mu \mathrm{m}$. The output of the best MP tape is predicted to be -19.2 $\mathrm{dBV}$ at $1.0 \mu \mathrm{m}$ and $-27.1 \mathrm{dBV}$ at $0.5 \mu \mathrm{m}(+3.8 \mathrm{~dB}$ and 
$-0.4 \mathrm{~dB}$ with respect to the measured $\mathrm{ME}$ tape results). For the thinnest MP tapes considered the PW50 values are still larger than those of the commercial ME tape. This may reflect some intrinsic advantages of ME tape, such as cooperative switching and very narrow switching field distributions. [4] Alternatively MP tapes thinner than those considered here are predicted to have smaller PW50 values (as seen in Fig. 3).

Table II. The effect of improvements in the magnetic properties on the calculated output signal. For these simulations $\mathrm{d}=35 \mathrm{~nm}$, and $\delta=0.2 \mu \mathrm{m}$.

$\begin{array}{ccccc}\text { Simul } & \mathrm{M}_{\mathrm{s}}(\mathrm{kA} / \mathrm{m}) & \mathrm{H}_{\mathrm{c}}(\mathrm{kA} / \mathrm{m}) & \mathrm{V}_{1.0}(\mathrm{dBV}) & \mathrm{V}_{0.5}(\mathrm{dBV}) \\ \mathrm{D} & 285.3 & 152 & -21.5 & -29.7 \\ \text { E } & 285.3 & 203.4 & -21.4 & -28.7 \\ \text { F } & 373.8 & 152 & -19.3 & -28.2 \\ \text { G } & 373.8 & 203.4 & -19.2 & -27.1\end{array}$

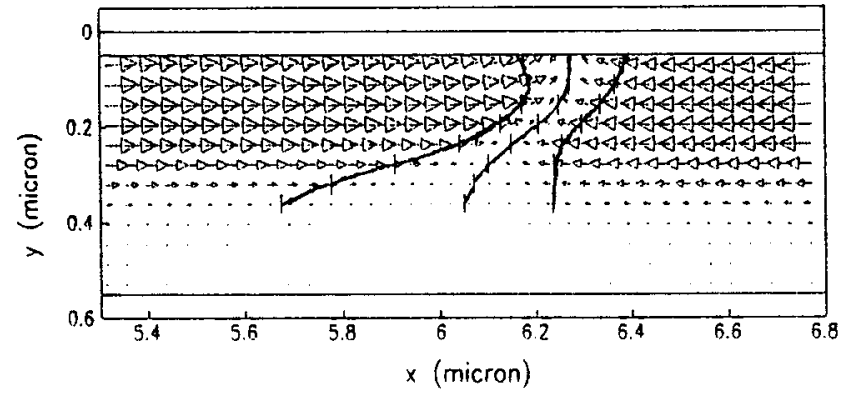

Fig. 4a Schematic of the calculated magnetization pattern in an MP tape $(d=50 \mathrm{~nm}, \delta=0.5 \mu \mathrm{m})$ in the vicinity of a recording transition. The lines are guides to the eye and indicate the transition center and width (25-75\%). Note the different axes in Fig. 4b. In this simulation the head moved from right to left.

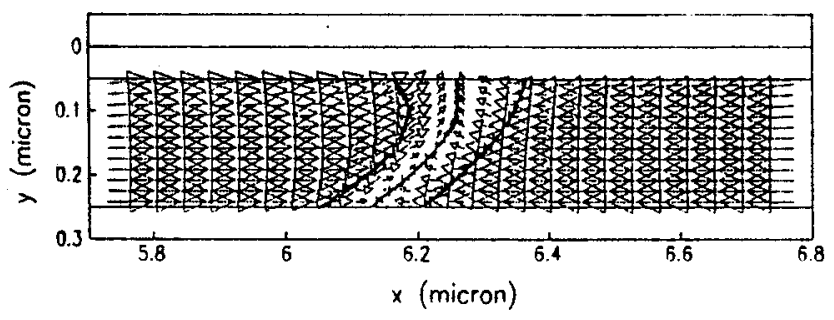

Fig. 4b Schematic of the calculated magnetization pattern in an MP tape ( $d=50 \mathrm{~nm}, \delta=0.2 \mu \mathrm{m})$ in the vicinity of a recording transition. The lines are guides to the eye and indicate the transition center and width $(25-75 \%)$. Note the different axes in Fig. 4a. In this simulation the head moved from right to left.

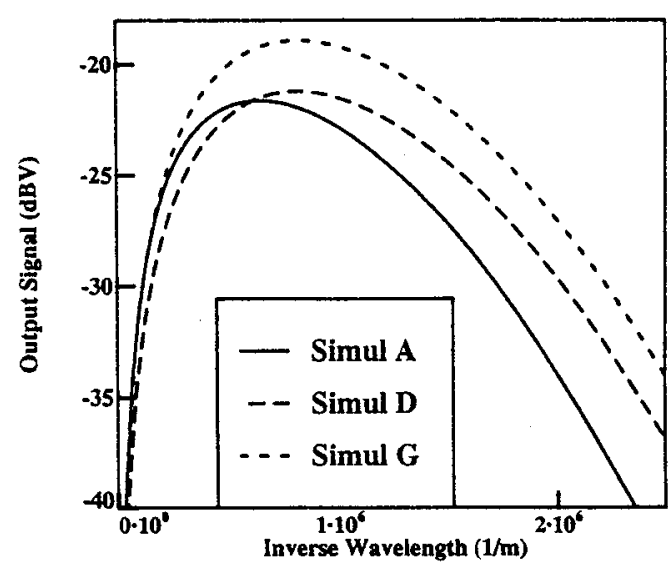

Fig. 5 Calculated output signal in $\mathrm{dBV}$ versus inverse wavelength in $\mathrm{m}^{-1}$ for several tape simulations.

The phase characteristics of the MP tapes differ from those of ME tapes. The phase at long wavelengths, determined by Fourier transforming pulse data (not shown here), in MP tapes has its origin in the asymmetry in the transition width about the transition center, as can be seen at large y values in Fig. 4a. The phase in ME tape has its origin in the oblique easy-axis orientation in ME tape. It is unlikely that this difference in phase between MP and ME tape can be eliminated in improved MP tapes. This will have consequences for digital systems which will use both ME and MP tapes (for example in the equalizer settings). The phase in MP tape could be adjusted by giving the particles in the MP tape a net oblique orientation. However the effect on the output signals from the MP tape is minimal (less than a $1 \mathrm{~dB}$ improvement in output signal at 1.0 and $0.5 \mu \mathrm{m}$ ), and since such tapes will still have a different phase than ME tape, an obliquely oriented MP tape is probably not worth the effort.

\section{CONCLUSIONS}

We have simulated geometric and magnetic improvements in MP tape. Decreasing the head-to-tape distance $d$, and increasing the saturation magnetization $M_{s}$ yielded the largest improvements. The simulated total improvements in the MP tape would allow it to exceed (a difference on the order of $4 \mathrm{~dB}$ ) the output signal at $1 \mu \mathrm{m}$, and approximately equal the output signal at $0.5 \mu \mathrm{m}$, of currently available commercial ME tapes. However improved ME tapes are expected.[2] The PW50 values and phase characteristics of the improved MP tapes are different than those for ME tapes. This will have consequences for digital systems which will use both ME and MP tapes. 


\section{REFERENCES}

1) H. Inaba, K.Ejiri, N.Abe, K.Masaki, and H.Araki, "The Advantages of the Thin Magnetic Layer on a Metal Particulate Tape", IEEE Trans. on Magn., vol. 29, pp. 36073612, November 1993.

2) K. Kanota, H. Inoue, A. Uetake, M. Kawaguchi, K. Chiba, and Y. Kubota, "A High Density Recording Technology for Digital VCR's", IEEE Trans. Consum. Elec., vol. 36, pp. 540-547, August 1990.

3) H.A.J.Cramer, "A Moving-Preisach Vector Hysteresis Model for Magnetic Recording Media", J. Magn. Magn. Mat., vol. 88, pp. 194-204, July 1990.

4) H.A.J.Cramer, "On the Hysteresis and the Recording Process in Magnetic Media", Ph.D. Dissertation, Twente University, 1993.

5) B.K. Middleton, "Recording and Reproducing Processes", in Magnetic Recording Volume I: Technology, C.D. Mee and E.D. Daniel eds. (McGraw-Hill Book Company, New York, 1987), Chapter 2.

6) S.B. Luitjens, G.J. van den Enden, and H.A.J. Cramer, "A Way to Assess the Performance of Heads and Tapes for Digital Video Recording", Proceedings of the 8th Audio, Video, and Data Recording Conference, Burmingham, UK, 1990, IEE Conf. Publ., vol. 319, pp. 43-49, 1990.

7) T. Kitahara, O. Simizu, and T. Nakao, "A Discussion of Particulate Media for Unsaturated Digital Recording",Report of the 83rd Meeting of the Japanese Society for Applied Magnetism on Storage for Multimedia Applications, pp. 101-107, January 1994. 